\title{
Is diabetes management in primary care improving clinical outcomes? A study in Qatar
}

I. Mochtar ${ }^{1,2}$ and M.F. Al-Monjed ${ }^{1,2}$

$$
\begin{aligned}
& \text { هل يحسّّن علاج السكّري في الرعاية الأولية النتائج السريرية؟ دراسة في قَطَر } \\
& \text { إقبال نختار، محمد فول عاز المنجدي }
\end{aligned}
$$

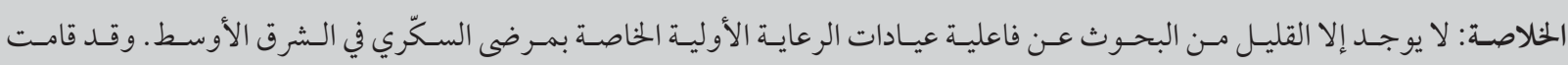

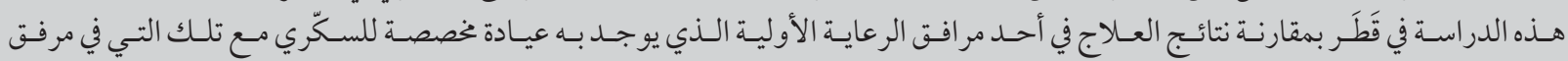

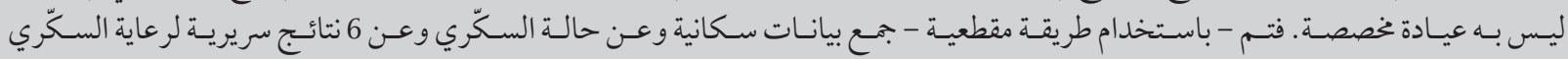

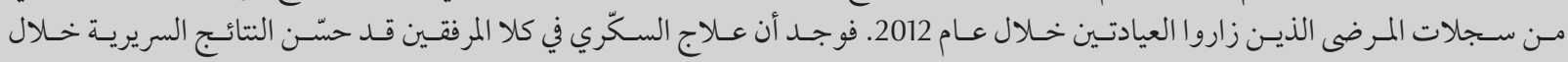

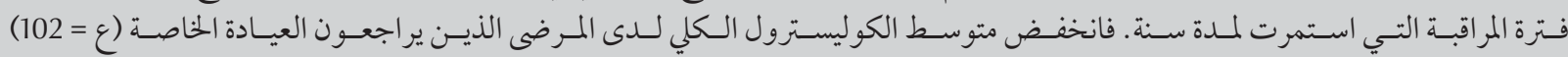

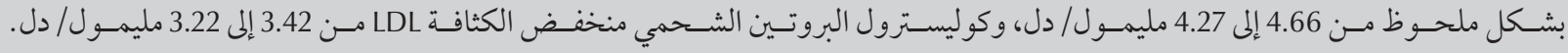

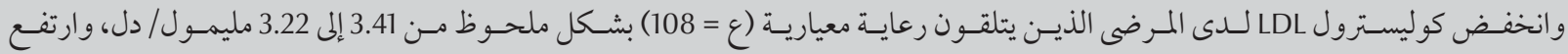

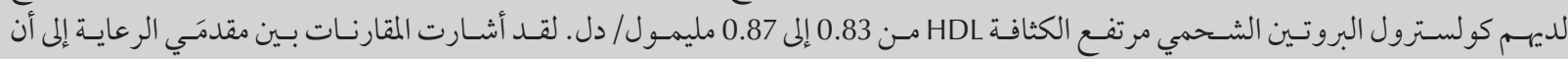

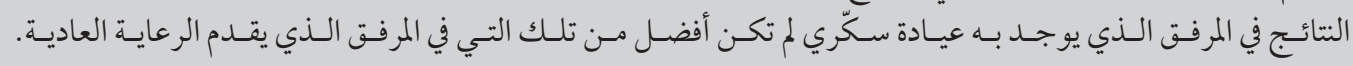

ABSTRACT There has been little research into the effectiveness of primary-care diabetes clinics in the Middle East. This study in Qatar compared patient outcomes at a primary-care facility with a dedicated diabetes clinic and one without. Using a cross-sectional method, data on demographics, diabetes status and 6 clinical outcomes of diabetes care were collected from the records of patients who visited the clinics during 2012. Diabetes management in both facilities improved clinical outcomes over the 1-year observation period. The mean total cholesterol of patients attending the special clinic $(n=102)$ decreased significantly from 4.66 to $4.27 \mathrm{mmol} / \mathrm{dL}$ and LDL cholesterol from 3.42 to $3.22 \mathrm{mmol} / \mathrm{dL}$. The LDL cholesterol of patients receiving standard care $(n=108)$ reduced significantly from 3.41 to $3.22 \mathrm{mmol} / \mathrm{dL}$ and $\mathrm{HDL}$ cholesterol increased from 0.83 to $0.87 \mathrm{mmol} / \mathrm{dL}$. Inter-provider comparisons indicated that the outcomes in the facility with a diabetes clinic were not superior to those in the facility with standard care.

La prise en charge du diabète en soins de santé primaires permet-elle d'améliorer les résultats cliniques? Étude au Qatar

RÉSUMÉ Très peu de recherches ont été menées sur l'efficacité des cliniques du diabète intégrées à des établissements de soins de santé primaires au Moyen-Orient. La présente étude menée au Qatar a comparé les résultats pour les patients d'un établissement de soins de santé primaires doté d'une clinique dédiée au diabète et d'un établissement ne disposant pas de service de ce genre. En recourant à une méthode transversale, des données démographiques, des informations concernant le statut diabétique des patients et six résultats cliniques liés aux soins du diabète ont été collectés à partir des dossiers des patients ayant consulté dans ces établissements en 2012. La prise en charge du diabète dans les deux types d'établissements avait amélioré les résultats cliniques sur la période d'observation d'un an. Le taux moyen de cholestérol total des patients consultant dans la clinique spécialisée ( $n=102)$ avait nettement diminué - de 4,66 à $4,27 \mathrm{mmol} / \mathrm{dL}$ - tandis que le cholestérol LDL était passé de 3,42 à 3,22 mmol/dL. Le cholestérol LDL des patients ayant reçu des soins généraux ( $n=108)$ avait nettement diminué - de 3,41 à 3,22 $\mathrm{mmol} / \mathrm{dL}$ - tandis que le cholestérol HDL avait augmenté, passant de 0,83 à $0,87 \mathrm{mmol} /$ dL. Les comparaisons entre les prestataires de soins ont montré que les résultats de l'établissement doté de la clinique spécialisée dans le diabète n'étaient pas supérieurs à ceux du service de soins généraux. 


\section{Introduction}

Diabetes is a chronic metabolic disorder characterized by an increased sugar level in the blood due to the impaired ability of the body to produce or respond to insulin. Diabetes has emerged as one of the most globally challenging chronic diseases; its prevalence has increased significantly over the past few decades. In 2000, the number of diabetes cases worldwide was 285 million and the cases are predicted to reach 439 million by 2030 (1). In Qatar, the number of people who had the disease was 38000 in 2000 and this figure is expected to rise to 88000 in 2030 (2). The prevalence of diabetes among Qatar's population in 2011 was $20.2 \%$ (3), which is almost 2.5 times the prevalence in the United States (4).

Primary care has been recognized as a strategic health institution for the management of chronic diseases, including diabetes (5). The World Health Organization and the United Kingdom Prospective Diabetes Study have highlighted that primary and secondary prevention of diabetes can be delivered efficiently in primary care (6-8). Currently, most diabetic patients are managed in primary health-care clinics (PHCCs) and only a small proportion of them visit specialists for regular treatment (9). Diabetes management in primary care, however, is variable in type and quality. Some PHCCs only provide a simple service such as a physician consultation and blood sugar test. Others provide a more comprehensive approach, combining physician consultation with other services such as health education/promotion, regular foot and eye examinations as well as early identification and control of cardiovascular disease risk factors.

To optimize the quality of care, some PHCCs run a special diabetes clinic aimed at providing individual and holistic management to diabetic patients. Such a clinic is usually staffed by a multidisciplinary team and utilizes agreed protocols in its activities. In diabetes clinics, diabetic patients may receive comprehensive care, including regular appointments, scheduled physician consultations, routine diabetic profile examinations, dedicated health education, dietary consultation and referral to specialists if required. Patients may also receive scheduled examinations of feet and eyes as well as screening of microand macrovascular complications.

In Qatar, most PHCCs provide diabetes care services. The types of services offered, however, differ from one provider to another, depending on the structure, level and resources available. Some PHCCs only provide a simple service, while others run dedicated diabetes clinics. Apart from the wide availability of diabetes services in primary care, there has been a lack of information regarding the effectiveness of PHCCs in diabetes management.

The objectives of this study were to evaluate and compare the outcomes of diabetes management in a PHCC in Qatar with a dedicated diabetes clinic and a PHCC with no special clinic. Until now, there have been no studies in the Middle East comparing the outcomes of diabetes management in primary care with and without a special diabetes clinic.

\section{Methods}

\section{Setting}

Facility A is a PHCC located in a downtown area of Messaied and offers services to around 10000 inhabitants in its area. Since 2009 the centre has run a special diabetes clinic aimed at providing comprehensive and standardized management for diabetic patients including screening of diabetes, routine assessment and treatment, early detection and care of complications such as diabetic foot, retinopathy and nephropathy. The clinic is staffed by a multidisciplinary team consisting of doctors and nurses who have an educational background and professional experience in diabetes management. The clinic opens daily during working hours. Each diabetic patient is allocated a 30-minute consultation and during this time patients receive a brief consultation from nurses (which is focused on health education and dietary consultation), examinations of anthropometry, eyes and feet, laboratory tests and a physician consultation.

Facility B a typical supporting PHCC that is located in a suburban area of Messaied, around $10 \mathrm{~km}$ from Facility A and serves a population of around 1500 people. Diabetic patients can come for routine consultation and care, but no comprehensive diabetes management is offered to them. The centre is staffed by 1 general practitioner and 5 general nurses and provides general health services, including diabetes management; however, no special diabetes clinic is available. The consultation time for each patient is 15 minutes and during this time the patient receives a physician consultation and occasional diabetes profile tests.

\section{Sampling}

Using a cross-sectional method, this study utilized a convenience sample, namely the data of patients who attended Facility A and Facility B during a period of 12 months (January to December 2012). A patient's data were included in the study if the patient made a minimum of 2 visits during 2012 and had at least 2 data points for comparison (baseline and follow-up data) for each clinical outcome measured.

\section{Data collection and analysis}

The data of patients were retrieved from an electronic medical information management system that was available in both clinics. Data of interest included patient demographics (age, sex, education and job), diabetes status (type and duration of diabetes), medication use and 6 clinical outcomes that were routinely measured in diabetes care [fasting 
blood sugar, glycated haemoglobin (HbAlc), total cholesterol, low-density lipoprotein (LDL) cholesterol, highdensity lipoprotein (HDL) cholesterol and random microalbumin/creatinine ratio] (10).

\section{Data analysis}

Based on the available data, we performed intra- and inter-provider comparisons. For the intra-provider comparison, we calculated the mean difference between the baseline and the average value of each clinical outcome in each clinic over a 1 -year period. The baseline value was defined as the first recorded value of each outcome in the year 2012 while the average value was defined as the average recorded value of each outcome over the year after the exclusion of the baseline value. For inter-provider comparisons, we differentiated the clinical outcomes in Facility A and Facility B by comparing the percentage change of each clinical outcome over the study period. The percentage change of each outcome was calculated as follows: average value - baseline value/baseline value $\times 100 \%$.

The percentage change might be either an increase or a decrease. The dependent t-test was used to calculate the significance of difference between the baseline and the average value of each diabetes outcome in each clinic, while the independent t-test was used to test the significance of the difference in each diabetes outcome existing between Facility A and Facility B. Statistical calculations were computed with SPSS, version 20.

\section{Results}

In 2012, a total of 120 patients visited the diabetes clinic in Facility A. Of those, 18 patients were excluded due to incomplete data (only visited the clinic once). In Facility B, 112 diabetic patients visited the clinic and 4 patients were excluded due to incomplete data.
Table 1 shows the sociodemographic and basic diabetes profiles of the patients. In both Facility A and Facility B most patients were male, with an average age of 45 years and had type 2 diabetes. In general, there were no significant differences between patients' profiles in Facility A and Facility B in terms of sex, mean age, age group, type of diabetes and medication use $(P>$ $0.05)$. The mean duration of diabetes in Facility B was 5.3 years, which was longer than that in Facility A (3.6 years). Most patients in both Facility A and Facility B worked as professionals. Apart from that, there was a significant difference in the job distribution between patients in Facility A and Facility B.

The result of the intra-provider comparison between Facility A and Facility B is presented in Table 2. Over a 1-year period, there were statistically significant improvements $(P<0.05)$ in 2 diabetes outcomes in both facilities. In Facility A, the mean total cholesterol of patients decreased from 4.66 to 4.27 mmol $(P=0.001)$ and the mean LDL cholesterol also decreased from 3.42 to $3.18 \mathrm{mmol} / \mathrm{dL}(P=0.007)$. The other diabetes outcomes in Facility A remained unchanged. In Facility B, significant improvements were observed in both LDL and HDL cholesterol levels. The mean LDL cholesterol of patients decreased from 3.41 to $3.22 \mathrm{mmol} /$ $\mathrm{dL}(P=0.006)$ while the mean HDL cholesterol increased from 0.83 to 0.87 $\mathrm{mmol} / \mathrm{dL}(P=0.035)$. Other outcomes did not change significantly $(P>0.05)$.

Table 3 shows the comparison between the percentage changes of diabetes outcomes over a 1-year period in both Facility A and Facility B. Compared with Facility A patients, Facility B patients had a greater reduction in LDL cholesterol ( $-4.0 \%$ versus $-3.8 \%)$ and fasting blood sugar $(-0.4 \%$ versus $0.04 \%$ ) as well as having a slower progression of microalbumin/creatinine ratio (93.1\% versus $134.6 \%$ ). The increased HDL cholesterol level was also more noticeable in Facility
B than Facility A (7.0\% versus 5.2\%). On the other hand, Facility A patients had a greater reduction than Facility $B$ patients in terms of total cholesterol $(-5.8 \%$ versus $-2.0 \%)$ and $\mathrm{HbAlc}$ ( $-1.4 \%$ versus $2.0 \%)$. Apart from that, none of these observed differences were statistically significant $(P>0.05)$.

\section{Discussion}

Initially we hypothesized that Facility A would yield better diabetic outcomes than Facility B. Facility A is a typical community PHCC and located in downtown, has adequate facilities and staff and is equipped with a special diabetes clinic that can facilitate the favourable factors for good diabetes achievement such as those related to the provider factor (the availability of health professionals with relevant educational background and experience) and the organization of care factors (the availability of adequate facilities, resources and a multidisciplinary team). On the other side, Facility B is a typical supporting PHCC, located in suburban area, has limited facilities and staff and has no special diabetes clinic.

The results of our study, however, showed that both Facility A and Facility B showed comparable improved outcomes. Over a 1-year period, Facility A produced significant improvements in patients' levels of total cholesterol $(-0.37 \mathrm{mmol} / \mathrm{dL})$ and LDL cholesterol $(-0.23 \mathrm{mmol} / \mathrm{dL})$, while Facility B yielded improvements in patients' LDL cholesterol $(-0.19 \mathrm{mmol} / \mathrm{dL})$ and HDL cholesterol $(0.03 \mathrm{mmol} / \mathrm{dL})$. In addition, our study found no significant differences between Facility A and Facility $B$ in terms of percentage changes of the 6 clinical indicators. The results of this study have certain implications.

First, while numerous studies reported inadequate diabetes management in primary care (11-13), our study observed improvements in 2 out of 6 clinical indicators in each PHCC. The results of this study support the 


\begin{tabular}{|c|c|c|c|c|c|c|c|}
\hline \multirow[t]{2}{*}{ Variable } & \multicolumn{2}{|c|}{ Total $(n=210)$} & \multicolumn{2}{|c|}{ Facility A $(n=102)$} & \multicolumn{2}{|c|}{ Facility B $(n=108)$} & \multirow[t]{2}{*}{$P$-value } \\
\hline & No. & $\%$ & No. & $\%$ & No. & $\%$ & \\
\hline Sex & & & & & & & 0.13 \\
\hline Male & 202 & 97.1 & 96 & 94.1 & 106 & 98.1 & \\
\hline Female & 8 & 2.9 & 6 & 5.9 & 2 & 1.9 & \\
\hline Means (SD) age (years) & \multicolumn{2}{|c|}{$45.3(15.1)$} & \multicolumn{2}{|c|}{$44.6(14.7)$} & \multicolumn{2}{|c|}{$46.2(15.2)$} & 0.13 \\
\hline \multicolumn{8}{|l|}{ Age (years) } \\
\hline$<45$ & 31 & 14.8 & 16 & 15.7 & 15 & 13.9 & \\
\hline $45-54$ & 130 & 61.9 & 63 & 61.8 & 67 & 62 & \\
\hline $55-64$ & 48 & 22.8 & 22 & 21.6 & 26 & 24.1 & \\
\hline$\geq 65$ & 1 & 0.5 & 1 & 1.0 & 0 & 0.0 & \\
\hline Occupation & & & & & & & 0.02 \\
\hline Professional/sedentary worker & 140 & 66.7 & 57 & 55.9 & 83 & 76.8 & \\
\hline Manual worker & 64 & 30.5 & 39 & 38.2 & 25 & 23.2 & \\
\hline Housewife & 5 & 2.4 & 5 & 4.9 & 0 & 0.0 & \\
\hline Other & 1 & 0.4 & 1 & 1.0 & 0 & 0.0 & \\
\hline Type of diabetes & & & & & & & 0.37 \\
\hline Type 1 & 6 & 2.9 & 4 & 3.9 & 2 & 1.8 & \\
\hline Type 2 & 204 & 97.1 & 98 & 96.1 & 106 & 98.2 & \\
\hline $\begin{array}{l}\text { Mean (SD) duration of diabetes } \\
\text { (years) }\end{array}$ & & & & & & & 0.02 \\
\hline Types of diabetes medications & & & & & & & 0.53 \\
\hline Oral & 136 & 64.8 & 69 & 67.6 & 67 & 62.0 & \\
\hline Insulin & 11 & 5.2 & 6 & 5.9 & 5 & 4.6 & \\
\hline Oral and insulin & 63 & 30.0 & 27 & 26.5 & 36 & 33.3 & \\
\hline Other medications & & & & & & & 0.46 \\
\hline Lipid lowering agents & 62 & 29.5 & 32 & 31.4 & 30 & 27.8 & \\
\hline Anti-hypertension & 30 & 14.3 & 13 & 12.7 & 17 & 15.7 & \\
\hline $\begin{array}{l}\text { Lipid lowering and anti- } \\
\text { hypertension }\end{array}$ & 99 & 47.1 & 45 & 44.1 & 54 & 50.0 & \\
\hline $\begin{array}{l}\text { No lipid lowering and anti- } \\
\text { hypertension }\end{array}$ & 19 & 9.0 & 12 & 11.8 & 7 & 6.5 & \\
\hline
\end{tabular}

$S D=$ standard deviation.

important role of primary care and are similar to the results of some studies demonstrating the effectiveness of diabetes management in primary care (14-16). In fact, systematic reviews indicated that the reports of some studies on deficient diabetes management in primary care are far from universal. If PHCCs implement a good standard of care, regular reviews and organized management, the outcomes of diabetes management in this setting could be comparable or even better than the management in hospital $(15,17)$.
In Qatar, the effectiveness of diabetes management in primary care has been studied by Bener et al. (18). Their study indicated that over a 1-year observation, diabetes management produced significant improvements in the proportions of patients who achieved normal fasting blood sugar (from 25.3\% to 31.0\%) and had HbAlC > 7\% (from $74.7 \%$ to $69.0 \%$ ). In addition, there were also improved means values of fasting blood sugar $(-0.76 \mathrm{mmol} / \mathrm{dL})$ and $\mathrm{HbAlC}$ $(-0.78 \mathrm{mmol} / \mathrm{dL})$, as well as systolic and diastolic blood pressures ( -4.9 and
$-2.3 \mathrm{mmHg}$ respectively). The study also concluded that compared with diabetes management in hospital, PHCCs yielded better clinical outcomes and patients' level of satisfaction (18).

While various factors could contribute to the favourable results at primary care facilitates in Qatar, we would highlight the potential contribution of socioeconomic factors. Qatar is an affluent country and most of its population, including residents living around Facility A and Facility B, enjoy a relatively high standard of living. Facility A and 
Facility B are situated near an industrial area and most of their catchment residents work as professionals in oil and gas companies. The residents have competitive earnings and are relatively well-off in terms of socioeconomic status. In our study, around $67 \%$ of diabetic patients worked as professionals and were assumed to have good socioeconomic status. Given their status, they could have better access to health institutions and care, be able to pay the costs of treatment, receive more health programmes and undergo more examinations. These favourable conditions could lead them to be more receptive to health management, to be more compliant and to have better health outcomes. Theoretically, diabetes outcomes are linked to socioeconomic status, as measured by the levels of income, education and job. Lower socioeconomic status has been associated with poorer glycaemic control, lower rates of blood sugar and $\mathrm{HbAlC}$ tests, limited physical exercise and poorer physical and mental health (19).

In addition, most residents in Qatar are covered by different types of health insurance, giving them adequate access to health care. Most of the catchment population of Facility A and Facility B had either government, local or company health insurance which entitled them to have access to health-care facilities for free or with a small fee. Patients' possession of health insurance is, in fact, an important factor influencing diabetes outcomes. Insured people with diabetes usually have more preventive health services, more eye and foot examinations as well as better glycaemic control (19).

Secondly, the provision of a structured diabetes programme, such as a special diabetic clinic, is not an absolute requirement for good diabetes management, and improved diabetes outcomes can be achieved even without the availability of a special diabetes clinic. In our study, the percentage changes of 6 clinical outcomes in Facility A over a 1-year observation were not different with those in the Facility B and this suggests that Facility A is not superior to Facility B in diabetes care. In fact, studies comparing diabetes management in primary care with and without special diabetes clinic provide inconsistent results. Some studies showed that the provision of a diabetes clinic yielded better glycaemic control, better follow-up and reduced hospitalization (20). Other studies, however, showed that diabetes clinics did not produce better outcomes than usual care (16). While the result of our study may support the view that care at special diabetes clinics is not superior to the usual care in primary care, it is worth discussing some factors that may contribute to the results of this study.

There is clear evidence that the outcomes of diabetes management depend not just on the provision of special diabetes clinic but also on many other interrelated factors, namely the patient, the provider and the organization of care (21). Patient factors are related to compliance, regular attendance, knowledge, attitudes, beliefs, individual characteristics, financial resources, comorbidities and social support. Provider factors includes health professionals' levels of education and experience, attitude, clinical inertia and ability to build a good doctor-patient relationship. Organization of care factor includes the provision of adequate facilities and resources, organized systems and a multidisciplinary team implementing agreed protocols, guidelines and educational programmes. A diabetes study in the Middle East pointed out the importance of effective communication and continuity of care as factors affecting quality of 


\begin{tabular}{|c|c|c|c|c|}
\hline Variable & $\begin{array}{c}\text { Facility A } \\
\text { Mean (SE) \% change }\end{array}$ & $\begin{array}{c}\text { Facility B } \\
\text { Mean (SE) \% change }\end{array}$ & $\begin{array}{c}\text { Difference A vs B } \\
\text { Mean (SE) }\end{array}$ & $P$-value \\
\hline Total cholesterol (mmol/dL) & $-5.82(2.27)$ & $-2.01(2.55)$ & $-3.81(2.71)$ & 0.161 \\
\hline LDL cholesterol (mmol/dL) & $-3.82(21.2)$ & $-3.96(2.89)$ & $0.18(3.05)$ & 0.952 \\
\hline HDL cholesterol (mmol/dL) & $5.24(3.33)$ & $6.95(3.32)$ & $-1.72(3.27)$ & 0.598 \\
\hline Fasting blood sugar (mmol/dL) & $0.04(4.62)$ & $-0.39(3.80)$ & $0.44(4.01)$ & 0.913 \\
\hline $\operatorname{HbA1c}(\%)$ & $-1.44(2.48)$ & $1.96(2.90)$ & $-3.46(2.35)$ & 0.143 \\
\hline Miroalbumin/ creatinine ratio $(\mathrm{mg} / \mathrm{mmol})$ & $134.60(68.0)$ & $93.10(30.7)$ & $34.10(81.4)$ & 0.676 \\
\hline
\end{tabular}

$S E=$ standard error; $L D L=$ low-density lipoprotein; $H D L=$ high-density lipoprotein; $H b A 7 c=$ glycated haemoglobin .

diabetic care in primary care (22). To achieve good diabetic care outcomes, health professionals should be able to communicate effectively with patients. Good communication will improve patients' satisfaction, motivation to adhere to medication and management as well as creating a trust in clinicians and the system. In terms of continuity of care, patients prefer to see the same doctor/ nurse during their regular visits because this increases patients' satisfaction, confidence and trust toward health professionals and will eventually improve their adherence to treatment.

Compared with Facility B, Facility A had a multidisciplinary team and ran the diabetes management in a more organized and comprehensive way. Apart from that, however, the staff in Facility A had a rotating schedule in the clinic and consequently patients usually saw different nurses/doctors when visiting the clinic. In the views of the patients, this situation may be considered as a lack of continuing care and therefore it may be speculated that this is a factor that affected the quality of care in Facility A.

In addition, our study only evaluated selected indicators of diabetes outcomes and therefore might not accurately reflect the comprehensive outcomes of diabetes management in both Facility A and Facility B. Up to now, there has been no international consensus on the agreed outcome indicators of diabetes management in primary care $(23,24)$. However, Wens et al. proposed 34 indicators that can be utilized in evaluating diabetic outcomes: 14 indicators for glycaemic control, 2 indicators for early detection of glycaemic complications, 4 indicators for treatment of glycaemic complications, 11 indicators for cardiovascular diseases and 3 indicators of quality of life (25). Contrary to Facility B, the diabetes clinic in Facility A not only provided glycaemic control, but also extended care, such as dedicated health education, early identification of diabetes complications as well as management of cardiovascular risk factors. The outcomes of this extended care, however, were not assessed in our study.

\section{Limitations}

Our study investigated the outcomes of diabetes management in only 2 PHCCs and the period of the study was limited to 1 year. While our study provides valuable information on diabetes outcomes in facilities with and without special clinics, the conclusion of this study might not reflect the real performance of all PHCCs in Qatar. The restricted period of the study was associated with the limited sample size, which may weaken the generalization of our study findings. The use of a fixed study period without masking the possible effects of previous treatments might contribute to an underestimation or overestimation of the real diabetic outcomes. To generate a more convincing conclusion representing primary care's performance in diabetes management in Qatar, other confirmatory studies involving more PHCCs and longer period of studies are required.
Also, the measured outcomes in this study were limited to only a few clinical indicators and therefore our study findings might not represent comprehensive diabetic outcomes. A more accurate result would be achieved if this study included more indicators of diabetes outcomes, such as those related to process measures, outcome measures, avoidable complications and hospitalization as well as patients' satisfaction.

\section{Conclusion}

Diabetes management in primary care resulted in improvements in some diabetic care outcomes. In the PHCC without a special diabetic clinic, significant improvements were noted in HDL and LDL cholesterol; while in the PHCC with a dedicated diabetic clinic, improvements were observed in total and LDL cholesterol. No evidence was found that the diabetes management conducted in a special diabetes clinic was superior to that in usual care.

\section{Acknowledgements}

The authors express special thanks to Dr Anwar Tag-Eldin (Lead Medical Officer, Department of Medical Service, Qatar Petroleum) and David Howarth of NGL Qatar Petroleum for his considerable support for this study.

\section{Funding: None.}

Competing interests: None declared. 


\section{References}

1. Shaw JE, Sicree RA, Zimmet PZ. Global estimates of the prevalence of diabetes for 2010 and 2030. Diabetes Res Clin Pract. 2010 Jan;87(1):4-14. PMID:19896746

2. Facts and figures about diabetes [Internet]. Geneva: World Health Organization; 2012. (http://www.who.int/diabetes/ facts/en/, accessed 8 March 2013).

3. The diabetes atlas. 5th ed. Brussels: International Diabetes Federation; 2011.

4. National diabetes fact sheet: national estimates and general information on diabetes and prediabetes in the United States. Atlanta: Department of Health and Human Services, Centers for Disease Control and Prevention; 2011.

5. Willens D, Cripps R, Wilson A, Wolff K, Rothman R. Interdisciplinary team care for diabetic patients by primary care physicians, advanced practice nurses, and clinical pharmacists. Clin Diabetes. 2011 Apr;29(2):60-8.

6. Prevention of diabetes mellitus. Report of WHO study group. World Health Organ Tech Rep Ser. 1994;844:1-100. PMID:7941615

7. UK Prospective Diabetes Study (UKPDS) Group. Intensive blood-glucose control with sulphonylureas or insulin compared with conventional treatment and risk of complications in patients with type 2 diabetes (UKPDS 33). Lancet. $1998 \mathrm{Sep}$ 12;352(9131):837-53. PMID:9742976

8. Morrison F, Shubina M, Goldberg SI, Turchin A. Performance of primary care physicians and other providers on key process measures in the treatment of diabetes. Diabetes Care. 2013 May;36(5):1147-52. PMID:23230095

9. Kirby MG. Sixty years of diabetes management in primary care. Br J Diabetes Vascular Dis. 2012 Nov-Dec;12(6):315-20.

10. American Diabetes Association. Standard of medical care in diabetes 2013-position statement. Diabetes Care. 2013 Jan;36(1):s11-66. PMID:23264422

11. Azab AS. Glycemic control among diabetic patients. Saudi Med J. 2001 May;22(5):407-409. PMID:11376381

12. Harris SB, Kapor J, Lank CN, Willan AR, Houston T. Clinical inertia in patients with T2DM requiring insulin in family practice. Can Fam Physician. 2010 Dec;56(12):e418-24. PMID:21156883

13. Spann SJ, Nutting PA, Galliher JM, Peterson KA, Pavlik VN, Dickinson LM, et al. Management of type 2 diabetes in the primary care setting: a practice-based research network study. Ann Fam Med. 2006 Jan-Feb;4(1):23-31. PMID:16449393

14. Farzadfar F, Murray CJL, Gakidou E, Bossert T, Namdaritabar $\mathrm{H}$, Alikhani S, et al. Effectiveness of diabetes and hypertension management by rural primary health-care workers (Behvarz workers) in Iran: a nationally representative observational study. Lancet. 2012 Jan 7;379(9810):47-54. PMID:22169105

15. Griffin S. Diabetes care in general practice: meta-analysis of randomised control trials. BMJ. 1998 Aug 8;317(7155):390-6. PMID:9694757

16. Ismail H, Wright J, Rhodes P, Scally A. Quality of care in diabetic patients attending routine primary care clinics compared with those attending GP specialist clinics. Diabet Med. 2006 Aug;23(8):851-6. PMID:16911622

17. Renders CM, Valk GD, Griffin SJ, Wagner EH, Eijk Van JT, Assendelft WJ. Interventions to improve the management of diabetes in primary care, outpatient, and community settings: a systematic review. Diabetes Care. 2001 Oct;24(10):1821-33. PMID:11574449

18. Bener A, Abdulmalik M, Al-Kazaz M, Mohammed AG, Sanya R, Buhmaid S, et al. Medical audit of the quality of diabetes care: is primary care more successful than hospitals? J Prim Care Community Health. 2012 Jan 1;3(1):42-50. PMID:23804854

19. Brown AF, Ettner SL, Piette J, Weinberger M, Gregg E, Shapiro $\mathrm{MF}$, et al. Socioeconomic position and health among persons with diabetes mellitus: a conceptual framework and review of the literature. Epidemiol Rev. 2004;26:63-77. PMID:15234948

20. Wagner EH, Grothaus LC, Sandhu N, Galvin MS, McGregor M, Artz K, et al. Chronic care clinics for diabetes in primary care: a system-wide randomized trial. Diabetes Care. 2001 Apr;24(4):695-700. PMID:11315833

21. Alberti H, Boudriga N, Nabli M. "Damm sokkor": factors associated with the quality of care of patients with diabetes: a study in primary care in Tunisia. Diabetes Care. 2007 Aug;30(8):20138. PMID:17507697

22. Al-Azri M, Al-Azri H, Al-Hashmi F, Al-Rasbi S, El-Shafie K, Al-Maniri A. Factors affecting the quality of diabetic care in primary care settings in Oman. A qualitative study on patients' perspective. Sultan Qaboos Univ Med J. 2011 May;11(2):207-13. PMID:21969892

23. Vrca-Botica M, Zelic I. Quality indicators for diabetic care in primary care. Diabetol Croat. 2007;36(2):31-2.

24. Calsbeek H, Ketelaar NA, Faber MJ, Wensing M, Braspenning J. Performance measurements in diabetes care: the complex task of selecting quality indicators. Int J Qual Health Care. 2013 Dec;25(6):704-9. PMID:24150483

25. Wens J, Dirven K, Mathieu C, Paulus D, Van Royen P; Belgian Diabetes Project Group. Quality indicators for type-2 diabetes care in practice guidelines: an example from six European countries. Prim Care Diabetes. 2007 Feb;1(1):17-23. PMID:18632015 